\title{
The influence of students' ICT skills and their adoption of mobile learning
}

\author{
Kathryn Mac Callum \\ Eastern Institute of Technology, New Zealand \\ Lynn Jeffrey \\ Massey University, New Zealand
}

\begin{abstract}
Mobile technology has gained increased focus in academic circles as a way to enable learning that is not confined by time and place. As the benefits of mobile learning are being clarified so too will researchers need to understand the factors that influence its future use. The adoption of mobile technology will largely depend on whether students believe that mobile technology fits their particular needs. However despite the interest in the potential of mobile learning, researchers have only a limited knowledge of the factors that may influence student adoption. To address this gap in the literature, the present study was undertaken to determine how ICT skills impact students' adoption of mobile learning. The study posited that the perceived ease of use and usefulness of mobile technology would mediate the relationship between ICT skills and the intention of students to adopt mobile learning. A survey of 446 students from three tertiary institutions found that students' intention to adopt mobile learning was influenced by specific types of ICT skills. In particular, it was found that advanced skill in mobile technology and basic ICT skills both played significant roles in the intention to adopt mobile learning. No evidence was found to support the assertion that advanced ICT skills influenced their adoption of mobile learning.
\end{abstract}

\section{Introduction}

Mobile technology has gained increased focus in academic circles as a way to enable learning that is not confined by time and place. A number of studies have looked at how mobile technology can be harnessed to elicit the potential benefits it affords both students and educators (for more details see Aubusson, Schuck, \& Burden, 2009; Churchill \& Churchill, 2008; Naismith, Lonsdale, Vavoula, \& Sharples, 2005). As these benefits of mobile learning are being clarified so too will researchers need to understand the factors that influence the future use (adoption) of mobile learning. The adoption of mobile technology will largely depend on whether students and educators believe that mobile technology fits their particular needs. The decision to adopt mobile learning is a complex process with a large number of influencing factors. Of these factors, one that has received limited attention is the influence that students' information and communication technology (ICT) skills and experience has on their adoption of mobile learning. In those studies that have considered this relationship, ICT skill has been used as a broad construct (see for example Williams, 2009; Theng, 2009; Lu \& Viehland, 2008; Kenny, Park, Van Neste-Kenny, \& Burton, 2010) that that does not allow for possible differential effects from different types of ICT skills.

Several researchers have attempted to develop models and conceptual frameworks to explain and analyse mobile learning (see Pachler, Bachmair \& Cook, 2010 for a review of some of these models). These models place mobile learning in a conceptual framework that helps to explain where mobile learning fits within the educational context. In addition to this, a number of these theories have been modified to explain student acceptance of mobile learning and ultimate adoption of it in an educational context. Theories such as diffusion of innovation (Rogers, 2003), the theory of reasoned action (Ajzen \& Fishbein, 1980), the theory of planned behaviour (Ajzen, 1991), the technology adoption model (TAM) (Davis, 1989) and the unified theory of acceptance and use of technology (UTAUT) (Venkatesh, Morris, Gordon, \& Davis, 2003) have been updated to model mobile learning adoption (see Venkatesh, et. al., 2003 for more detail on each of these models). These models provide insight into factors that influence users' acceptance of mobile learning. User acceptance has been defined as "the demonstrable willingness within a user group to employ information technology for the tasks it is designed to support" (Dillon \& Morris, 1996 , p. 5). In the context of mobile learning, user acceptance and adoption can be expressed as the willingness of students to use their mobile devices to support their learning. 
The TAM model has been used extensively in educational settings to determine adoption of instructional technology by educators and students. The TAM has also been modified and extended to include a range of additional antecedent variables to improve its predictive powers, including subjective norms, experience and motivation (Venkatesh, et al., 2003). One of the additional variables that have been associated with the TAM model is the measure of a user's self-efficacy. A large body of research has shown that a user's self-efficacy for using computing technology plays a significant role in the adoption of a wide range of learning tools (for example Beas \& Salanova, 2006; Shih, 2006). However, self-efficacy has only been examined in a relatively small number of studies on mobile learning adoption (for example Chen, Chen \& Yen 2011; Kenny et al., 2010).

\section{The technology adoption model}

Modelling the adoption process clarifies the factors that influence a user's uptake of a particular technology. One of the most widely adopted models used to explain adoption is the technology acceptance model (TAM). Davis (1989) developed the TAM to address the issue of how users come to accept and use a technology. The model identifies two variables: perceived ease of use; and usefulness, to be fundamental determinants of user acceptance (Venkatesh et. al, 2003). The TAM is a theoretical model used to model the causal linkages between perceived usefulness and perceived ease of use and a user's intention and actual computer adoption behaviour (Teo, 2010).

Even though the TAM has been widely used, it has been criticised by some researchers for not giving consistent and conclusive results (Ma \& Liu, 2004; Lee, Kozar, \& Larsen, 2003; Venkatesh \& Davis, 2000). With the aim of addressing this criticism Ma and Liu (2004) conducted a meta-analysis of empirical studies with the TAM. Based on the assessment of 26 studies they concluded that the TAM does provide a good tool for determining technology adoption. They found evidence of a strong relationship between perceived usefulness and behavioural intention, and between perceived ease of use and perceived usefulness. However, the weaker relationship between perceived ease of use and behavioural intention suggested that perceived ease of use operates through perceived usefulness. Based on this finding Ma and Liu (2004) proposed a new model where perceived ease of use is moderated by perceived usefulness, however, these changes have not been widely adopted. Despite these criticisms the TAM has continued to be widely used and has shown good predictive capabilities.

\section{Self-efficacy and mobile learning adoption}

Self-efficacy relates to the way individuals determine the choices they make regarding the effort, perseverance and anxiety they experience when engaged with a particular task (Usher \& Pajares, 2008). According to Wilson, Kickul, and Marlino (2007), individuals with high levels of self-efficacy have a greater chance of succeeding in the given task. Self-efficacy is seen as a key element that determines what activities individuals engage in, the effort they put into pursuing the activity, and the persistence they show in the face of adversity (Downey \& McMurtrey, 2007).

ICT self-efficacy stems from the social cognitive theory of self-efficacy belief (Eastin \& LaRose, 2000). In particular ICT self-efficacy is a subset of self-efficacy and has been described as an individual's judgment of their capability to use ICT (Compeau \& Higgins, 1995). As described in Embi (2007), computer self-efficacy is the measure of a user's confidence to use, understand and apply their computer knowledge and skills. ICT self-efficacy is simply a broader view of computer self-efficacy that incorporates both computer and digital communication devices.

Higher levels of confidence, when using ICT, have been shown to be positively related to users having stronger feelings of competence when using a range of computing tools. Users with higher levels of selfefficacy will typically set higher goals for themselves and be more resistant to failure (Claggett \& Goodhue, 2011). These users are more willing to use a computer and other technology and are more likely to feel that they will succeed in their tasks when using these tools (Cázares, 2010). On the other hand, users with a low level of confidence are less likely to use technology and will typically believe that technology is hard to use (Cázares, 2010). 
The measure of ICT self-efficacy typically includes a measure of prior experience with technology. Prior experience is the amount of time an individual has spent working with computers and the different applications they have learnt to use (Paraskeva, Bouta, \& Papagianni, 2008). A user's past ICT experience has been consistently reported in the literature as having a positive relationship with their self-efficacy beliefs (Hasan \& Ahmed, 2010; Potosky, 2002). The relationship that past experience has on an individual's self-efficacy has been highlighted in social cognitive theory, which states that prior experience represents the most accurate and reliable source of self-efficacy information about similar tasks (Hasan \& Ahmed, 2010).

In relation to mobile learning adoption and self-efficacy, research has shown that the level of experience a user has with mobile technology will influence their perception of the level of effort they need and the ease of using mobile learning (Wang, \& Wang, 2009). Venkatesh, et al. (2003) described the way effort expectancy was more significant for individuals with less experience. An individual with high mobile self-efficacy was more likely to see mobile learning as requiring less effort and be easier to use. This relationship between mobile self-efficacy (measured in terms of users' attitudes), perceived ease of use and adoption of mobile technology has been confirmed in a number of studies (Akour, 2009; Lu \& Viehland, 2008; Park \& Chen, 2007). Theng (2009) found that mobile self-efficacy played an important role in perceived usefulness especially in the form of a user's prior experience of using mobile devices. He found that a student with prior experience of using mobile devices perceived mobile learning as easy to use. This finding further supports Venkatesh et al.'s (2003) who found that experience played a role in technology adoption. Research has also shown that prior mobile experience can also influence how useful an individual perceives mobile learning to be (Akour, 2009). These findings, however do not consider the role of different types of previous skill and in particular whether a student with high computing skills would generally demonstrate a higher perception of ease of use and perceived usefulness of mobile technology. Thus the role of previous experience of ICT and its mediating role on future intention to adopt mobile learning are still relatively unclear.

While research on the adoption of technology by students and educators indicates some of the factors that may be important in the introduction of mobile learning, this insight has been too general and lacking in context to be useful to institutional decision-makers considering mobile-learning. The more specific, small scale trials and pilots that have been undertaken on mobile learning adoption to date (Akour, 2009; Uzunboylu \& Ozdamli, 2011; Williams, 2009), while interesting, lack the scale to give substantial confidence in the results. This study used a large sample to identify factors that influence acceptance of mobile learning by students in a New Zealand context and to build a cognitive framework that models the acceptance of mobile learning of students.

\section{Methodology}

The aim of this study was to model how the perceived ease of use and usefulness of mobile technology (based on the TAM) would mediate the relationship between self-efficacy beliefs (as measured by previous experience) and the intention of students to use mobile learning in the future. The population of interest in this study was tertiary students. A multi-stage stratified convenience sampling method was adopted for surveying three tertiary institutions in four geographic locations in New Zealand, using a combination of site-visits and electronic methods. A questionnaire was used to assess the respondents ICT skills and attitudes towards the integration of mobile technology in the tertiary learning environment.

Classes were randomly selected from the business courses listed on the University/ Polytechnic course calendars. The section of this sampling technique enabled the most effective coverage of the population (Punch, 2009; Zikmund, 2000). We first approached the course coordinator seeking permission to speak to their students about the research. Of the 23 classes approached three classes were unable to participate as they were already participating in another study. Therefore an additional three classes were selected to replace the original three. Each class was addressed by us and introduced to the study; students were given information sheets informing them of their rights in relation to this study, details of the study and an URL to the online questionnaire. Classes were given the option to complete the questionnaire online or using a hard copy. Approximately $30 \%$ of the questionnaires were completed in hard copy and the rest were completed online. After the classes had been spoken to, an email was sent via the course website to all students registered on the course. This email once again briefly outlined the study and contained the link to the research questionnaire that was also included the information sheet. 
Courses included in this study were from a range of academic levels. Of the estimated 1213 students invited to take part (based on numbers enrolled in each course supplied by the course coordinator of each course), 446 completed the questionnaire giving a response rate of $37 \%$. Of the 446 students 298 were from the University sector and 148 were from the Polytechnic sector.

The resulting sample size of the student group was adequate for testing purposes (Chin \& Todd, 1995; Ding, Velicer, \& Harlow, 1995). There is little agreement on the number of responses appropriate for structural equation modelling (Sivo, Fan, Witta, \& Willse, 2006). However Hoelter (1983) and Hoe (2008) recommend a sample size of 200 would be suitable for this type of statistical analysis. To eliminate bias it is recommended that studies with "three or more indicators per factor, a sample size of 100 will usually be sufficient for convergence and a sample size of 150 "will usually be sufficient for a convergent and proper solution" (Anderson \& Gerbing, 1984, pp. 171-170). While the sample size was suitable for most statistics, it was not large enough to allow for cross-validation of the structural equation model, since splitting the sample would have resulted in groups too small to reliably compare (Chin \& Todd, 1995; MacCallum, 1986). Cross-validating is a relatively complex process of randomly splitting a sample into two or more groups to allow for comparison between the samples. This is used to confirm that the outcomes are consistent between the samples and have not occurred by chance (Schumacker \& Lomax, 2010).

\section{Instrument development}

The questionnaire contained 50 self-reported items related to two research constructs. The TAM was used to determine students' future adoption of mobile learning. The two constructs of the TAM have been established to determine intention to adopt (Venkatesh, et al., 2003). In this study perceived usefulness and ease of use were assessed using 7 items based on a 7-point likert scale where 1 (strongly disagree) and 7 (strongly agree). The ease of use construct measured whether mobile technology was seen to be free from effort. The perceived usefulness construct measured whether mobile learning was perceived as being beneficial to teaching and learning. Questions included: "Mobile technology will enable me to access learning content more often" for perceived usefulness and "I think it might take me awhile to get comfortable with using a mobile device for learning" for ease of use. One question was used to capture the students future intention to adopt mobile learning, "Overall, I think mobile learning would be beneficial to my learning and I would be willing to adopt it, if I had the opportunity, in the future".

Based on the TAM model three hypotheses were tested:

- H1: Students who perceive mobile learning as easy to use will have a more positive perception of mobile learning usefulness.

- H2: Students who perceive mobile learning as useful will be more likely to indicate that they intend to adopt mobile technology.

- H3: Students who perceive mobile learning as easy to use will be more likely indicate that they intend to adopt mobile technology.

The ICT skills scale was made up of several technology tasks. Participants were asked to rate their skill on each task. The tasks used in this study were taken from Kennedy, Dalgarno, Bennett, Judd, Gray, and Chang (2008). The study conducted by Kennedy et al. (2008) included determining the most commonly used technology-based activities of student and staff. The original survey contained 38 tasks that were grouped into eight categories. A pilot test was used to reduce this number to 16 key activities that related to both computer and mobile usage. Computer based activities required a range of skills from using word processing software to searching and downloading files from the Internet. Mobile device usage included items relating to activities such as sending and receiving texts to uploading programs onto their phone. The skills were assessed based on a 7-point scale: $1=$ never used to 7=extremely skilled.

This study will therefore test the relationship that ICT skill has on mobile learning adoption. In particular, the following theoretical hypotheses will be tested:

- H4-6: Students with higher levels of basic ICT skills (H4), advanced ICT skills (H5) and/or advanced mobile skills (H6) will more likely to see mobile learning as easy to use and useful. 
- H7-9: Students with higher levels of basic ICT skills (H7), advanced ICT skills (H8), and/or advanced mobile skills (H9) will be more likely to adopt mobile learning.

In addition, the following relationships will be tested.

- H10-12: As users become more skilled in one area of ICT usage they will be more likely to adopt a wider use of a range of ICT technologies.

Figure 1 displays the hypothesised model.

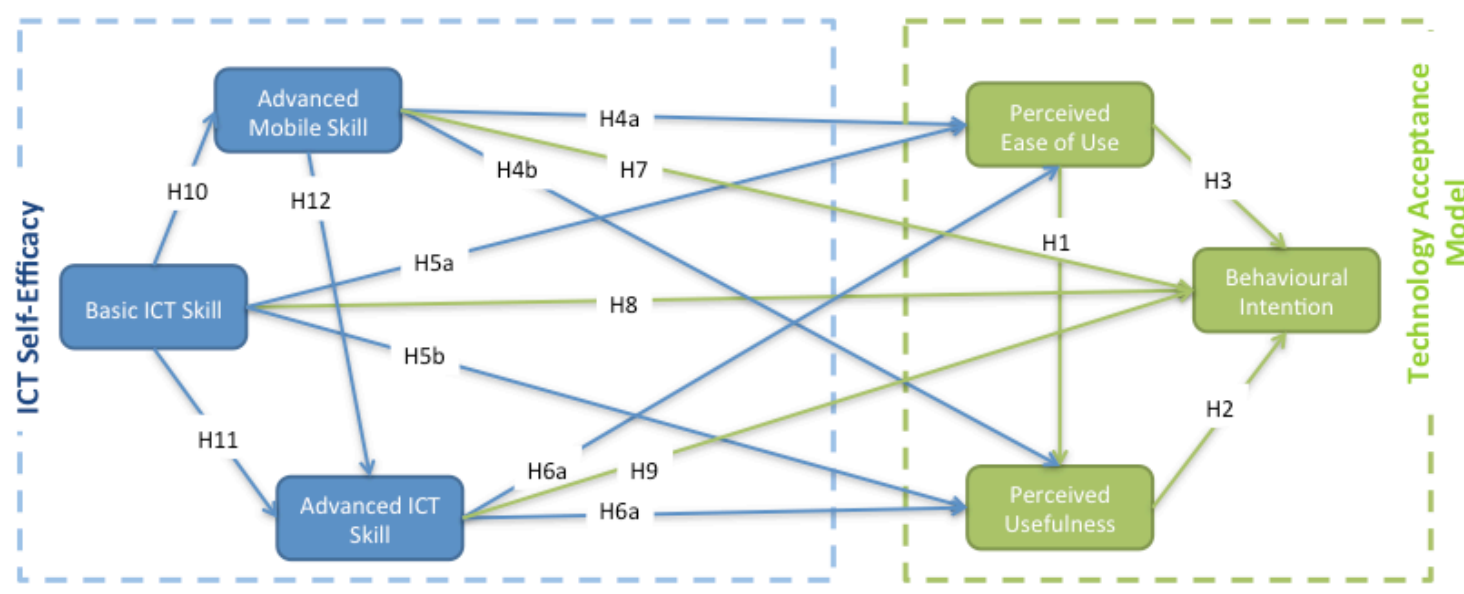

Figure 1. The tested model of students' adoption of mobile learning.

\section{Data analysis and results}

Construct validity is referred to as the degree to which the constructs adopted represents the theoretical concepts (Colliver, Conlee, \& Verhulst, 2012). Convergent and discriminant validity are both subcategories of construct validity (Colliver, Conlee, \& Verhulst, 2012). The present study employed exploratory factor analysis (EFA) to extract three latent constructs from the 16 item measure for ICT skills. Based on EFA these 16 tasks were grouped into three key groups, namely tasks associated with everyday ICT usage (referred to as basic ICT skills), tasks associated with expert or specialised ICT usage (referred to advanced ICT skills) and tasks associated with mobile usage (referred to advanced mobile skills). In each category four items were retained to represent each construct. The items selected all had loadings greater than 0.7 as consistent with Mulaik \& Millsap (2000). Basic ICT skills assessed the competency of users in relation to general computing tasks, such as using word processing software, searching and emailing on the Internet and doing basic mobile activities, such as texting and calling. Advanced ICT skills assessed the competency of users in relation to more advanced computing, such as modifying images and sounds and using advanced software (such as Skype). Basic mobile skills related to using mobile technology for more complex mobile learning activities, such as accessing the Internet, emailing and sending photos. In each category four items were retained to represent each construct. Based on the results of the EFA on mobile attitudes two constructs of perceived usefulness and ease of use were represented by four items that were deemed to represent these two constructs.

The composite reliability (internal consistency reliability) approach was estimated using Cronbach's alpha. Composite reliabilities of constructs ranged between 0.71 and 0.93 , exceeding the threshold of 0.7 (Nunnally, 1978).

The results were analysed using structural equation modelling. Structural equation modelling enables a complex analysis of theoretical models, testing of hypothesises and drawing inferences about the nature of causal relationships.

In total, 446 students participated in the study. Following data screening, a final sample of 413 was achieved. Of the 413 responses, there were 227 females (55\%) and 186 males (45\%). The mean students age was between the age of 20-29 years $(M=2.21 ; s=.991)$. The majority of participants classified themselves as European or part European $(68.3 \%)$. 


\section{Results}

Structural equation modelling was used to analyse the influence that skill has on perceived ease of use, perceived usefulness and behaviour intention. Figure 2 shows all the significant standardised path coefficients. The goodness of fit statistics showed a good fit for this model $\left(\chi^{2}=4.61, d f=6, p<.595\right.$, $\mathrm{SRMR}=.02, \mathrm{TLI}=.99, \mathrm{CFI}=.99, \mathrm{PCFI}=.40, \mathrm{RMSEA}=.0(90 \% \mathrm{CI}=.00-.06)$. All fit statistics except the $\chi^{2}$ p-value suggest a good fit. While chi-square $(\chi 2)$, its degrees of freedom $(d f)$ and p-value provide a baseline indication of model fit, $\chi^{2}$ has been shown to be a poor indicator of model fit, often producing false negatives (Byrne, 2010; Schumacker \& Lomax, 2004).

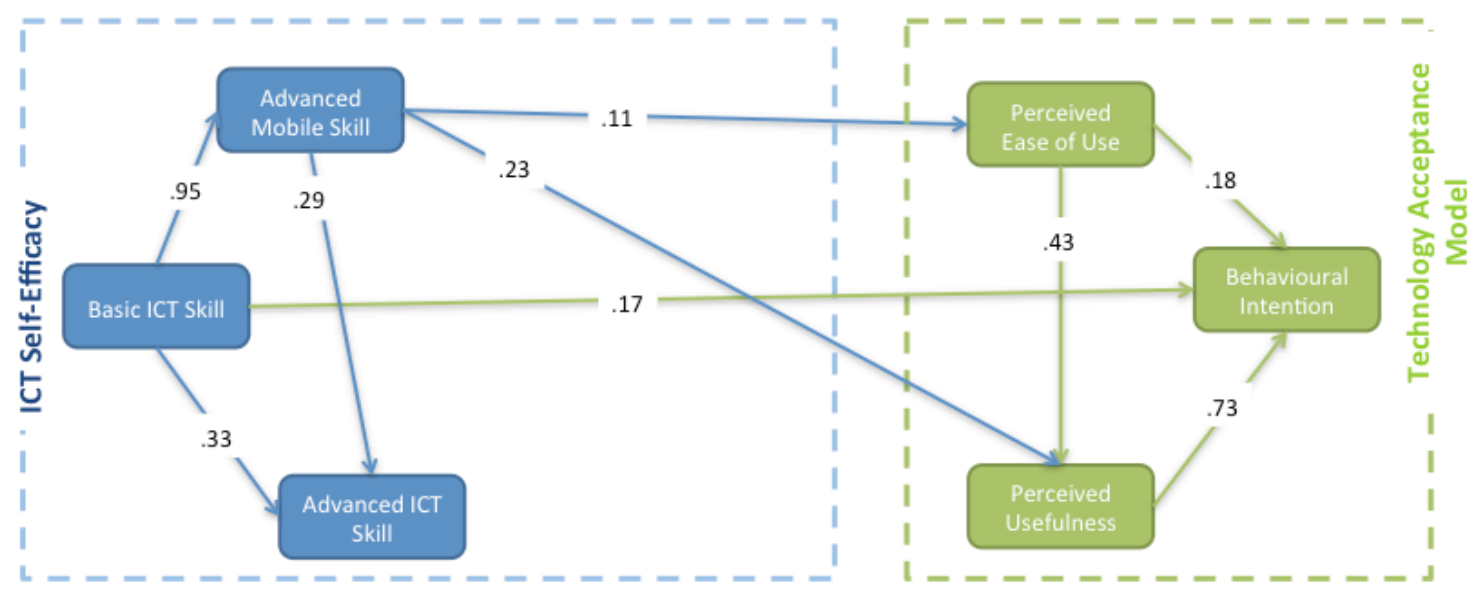

Figure 2. The results of structural modelling students' adoption of mobile learning.

The student adoption model confirmed that perception of ease of use and usefulness of mobile learning had the strongest influence on students' intention to adopt mobile learning. Good basic ICT skills are very strongly associated with advanced mobile, and also with advanced ICT skills. The model also establishes that to a lesser extent basic ICT skills play a direct role on their intention to adopt. The results indicate that students who are more skilled at a range of basic computing tasks are more likely to adopt mobile learning. Advanced mobile skills were shown to mediate the role of perceived ease of use and usefulness on the intention of students to adopt mobile learning. This indicates that a student's experience of mobile technology will influence their perceptions of mobile learning.

\section{Discussion}

Previous research has consistently reported a positive relationship between past ICT experience and selfefficacy beliefs (Hasan \& Ahmed, 2010; Potosky, 2002). However, these studies have not considered the impact that different types of previous skills might have on perception of ease of use and usefulness for a particular technology. In this study three types of ICT skills were identified, basic ICT skills, advanced ICT skills and advanced mobile skills, and tested for their influence on mobile learning adoption.

The study showed that perceived usefulness had the strongest influence on intention to adopt, followed to a lesser extent by perceived ease of use. However, ease of use had an additional indirect impact on intention to adopt through it strong influence on perceived usefulness. This suggests that if students are to adopt mobile learning they must see it as being easy to use, and believe that it offers major benefits over existing learning methods.

The study also showed that the influence of skill and experience with mobile technology on the adoption of mobile learning is mediated through the impact of perceived usefulness and ease of use. This suggests that students with a significant level of experience in the more advanced features of mobile technology will be both comfortable with using it for learning as well as able to see the benefits it offers in supporting their learning. The influence of mobile technology experience on mobile learning adoption has only been addressed in a few studies (for example, Theng, 2009). This finding provides further support for the 
notion that past experience with a specific technology is a key determinant of the future adoption of that technology (Saadé \& Kira, 2009).

The influence that experience had on perceived usefulness suggests that users are able to evaluate more accurately how valuable mobile learning will be in supporting their learning. Familiarity with a specific technology will help support the extension and experimentation with related forms of technology. In addition as users become more familiar with the technology they see more ways it could be used. In particular as the user becomes more skilled in using mobile technology they will be more likely to explore new mobile uses. A person that seldom uses mobile technology or has a low level of skill with the technology is less likely to experiment or deviate from existing use and is therefore less likely to see mobile learning as easy to use. Compared with unskilled and tentative users, confident users would be more likely to expand the use of the device and learn new tricks and ways to increase the efficiency of the device. This supports Lefoe, Olney, Wright, and Herrington (2009) who found that educators who became more familiar with their mobile devices developed a better understanding of how mobile learning activities could be developed and incorporated, and in particular the affordances which mobile technology offered education.

It was found that students who were competent basic ICT users were more likely to adopt mobile learning. The study showed that there was a direct relationship between basic ICT skills and intention to adopt mobile learning, not mediated by either perceived ease of use or usefulness. This finding clarifies for the first time, the influence of basic ICT skills on mobile learning adoption, a relationship that has not previously been explored in the literature. This suggests that the intention to adopt a new technology is enhanced by a minimum skill level in a range of basic computing tasks. This finding underlines the importance of the role that basic ICT skills play in the adoption of new technology. It signals that users with a basic level of ICT skills are more likely to perceive new technology as favourable and adopt it in the future. This notion is supported by the strong relationship between basic ICT skills, and advanced mobile skills and advanced ICT skills. Basic ICT skills seem to be an important building block for developing new or advanced skills in other technologies. The introduction of a specific technology may be more effective if the intended users first had a basic grounding in general computer skills.

While at the level of introducing new technology, very specific relationships were found between extant skills and the intention to use a new technology, the model also suggests that being skilled in one area promotes the development of skill in others areas. Highly skilled users in one area were likely to be highly skilled in other technology areas. As Shih, Muñoz \& Sánchez (2006) explained, the layering of skills show that confidence and favourable experiences in ICT will build on each other, such that users are more likely to learn new skills as they get more competent with their existing skills (Shih, et al., 2006). However, beyond the influence of a basic level of ICT and an advanced level of mobile skills, no additional influence on intention to adopt a new technology is apparent.

When preparing students for mobile learning, a wider focus is needed on how ICT is supported and introduced. Educators need to be aware that a basic level of ICT skill is recommended before students are introduced to mobile learning. Since many of the activities carried out on a mobile device are also undertaken on a computer, it may be beneficial to learn how to effectively carry out them on computer before progressing to a mobile environment. Activities such as email and surfing the Internet are both possible using a computer and a mobile device. If a user is familiar and comfortable with carrying out these tasks on a computer it may be less daunting to carry out these tasks on a smaller device such as mobile phone.

This study found no evidence that advanced ICT skills influenced the intention to adopt mobile learning. The finding that advanced ICT skills did not play a significant role on the perception of ease of use or usefulness is interesting and new. It also strengthens the argument that basic ICT skills and skill in a related technology are important keys to adoption. This finding suggests that advanced skills in unrelated technologies have no discernible influence on the adoption of a specific technology. Previous research does not seem to have investigated the relationship between the specific areas of ability and adoption. However, further research is necessary to determine whether these links are found in other contexts and to clarify the mechanism that explains it. 


\section{Conclusion}

The investment in new technology is an expensive and time consuming proposition, and the possibility of failure is very real if not properly considered. Often decisions to introduce new technology fail to consider student perspectives, risk wasting effort and resources, and risk a failure to realise the full benefits of the new technology (Birch \& Burnett, 2009; Hsbollah \& Idris, 2009). Thus user acceptance is an important factor in determining the adoption of mobile learning, and in higher education, the success of mobile learning depends upon student acceptance of the technology. Research has shown that the perceptions of students will play an important role in the success of any new venture, as it is the students who will be using the technology in their learning (Lu \& Viehland, 2008). This study has highlighted the important role that specific prior skill and experience have on students' perceptions of mobile technology. It shows that students with strong basic ICT skills exhibit a relatively high intention to adopt. Students with advanced mobile technology skills are more likely to perceive mobile learning as easy to use and useful. This study therefore points to the importance of anticipating students' negative attitudes stemming from low ICT self-efficacy. By providing support, and scaffolding ICT experiences, they can be helped make mobile learning seem less daunting and encourage adoption. Support and guidance is therefore seen as vital to support the ease and willingness of users to trial and adopt mobile technology.

This study aimed to establish some of the groundwork for further understanding of influences on the adoption of mobile learning. Support was found for some of the previous small-scale work done on mobile learning and new findings were also made. However, this was a cross-sectional study and longitudinal research is needed to establish the causality of relationships identified more firmly. In addition, the study itself was based on the TAM. The TAM starts from the position that people are already using the particular technology and then predicts future use. This study did not assume that participants had any experience of mobile learning but relied on users' experience with mobile technology. Participants were expected to project their understanding of mobile technology to a situation of using that technology for learning. This approach of developing a mobile learning adoption model based on limited experience is not new and a number of studies have used this same approach (Akour, 2009; Theng, 2009). In addition, future usage was calculated from a stated intention to adopt. Extensive empirical research has confirmed the causal link between intention to adopt and actual future adoption therefore giving some credence to using behavioural intention as an indicator of actual future adoption (Davis, 1989; Dillon, 2001; Venkatesh \& Davis, 2000).

In summary, while this study is not without limitations, the methods adopted resulted in significant findings in an area that is new and emerging with little empirical research. Overall even considering the limitation, these findings add significant value o to our understanding of mobile learning adoption.

\section{References}

Ajzen, I. (1991). The theory of planned behavior. Organizational Behavior and Human Decision Processes, 50, 179-211.

Ajzen, I., \& Fishbein, M. (1980). Understanding attitudes and predicting social behavior. Englewood Cliffs, NJ: Prentice-Hall.

Akour, H. (2009). Determinants of mobile learning acceptance: an empirical investigation in higher education (Doctoral dissertation). Retrieved from ProQuest Dissertations \& Theses database. (UMI No. AAT 3408682)

Anderson, J. C., \& Gerbing, D. W. (1984). The effect of sampling error on convergence, improper solutions, and goodness-of-fit indices for maximum likelihood confirmatory factor analysis. Psychometrika, 49(2), 155-173. doi:10.1007/BF02294170

Aubusson, P., Schuck, S., \& Burden, K. (2009). Mobile learning for teacher professional learning: benefits, obstacles and issues. ALT-J: Research in Learning Technology, 17(3), 233-247. doi:10.1080/09687760903247641 
Beas, M. I., \& Salanova, M. (2006). Self-efficacy beliefs, computer training and psychological well-being among information and communication technology workers. Computers in Human Behavior, 22(6), 1043-1058. doi:10.1016/j.chb.2004.03.027

Birch, D., \& Burnett, B. (2009). Advancing e-learning policy and practice: influences on academics' adoption, integration and development of multimodal e-learning courses. In M. Stansfield \& T. Connolly (Eds.), Institutional transformation through best practices in virtual campus development: advancing e-learning policies (pp. 65-80). Hershey, PA: Information Science Reference (IGI Global).

Byrne, B. M. (2010). Structural equation modeling with AMOS: Basic concepts, applications and programming (2nd ed.). Ottawa, Canada: Routledge.

Cázares, A. (2010). Proficiency and attitudes toward information technologies' use in psychology undergraduates. Computers in Human Behavior, 26(5), 1004-1008.

Chen, K., Chen, J. V., \& Yen, D. C. (2011). Dimensions of self-efficacy in the study of smart phone acceptance. Computer Standards \& Interfaces, 33(4), 422-431. doi:10.1016/j.csi.2011.01.003

Chin, W. W., \& Todd, P. A. (1995). On the use, usefulness, and ease of use of structural equation modeling in MIS research: a note of caution. MIS Quarterly, 19(2), 210-237. doi:10.2307/2

Churchill, D., \& Churchill, N. (2008). Educational affordances of PDAs: A study of a teacher's exploration of this technology. Computers \& Education, 50(4), 1439-1450. doi:10.1016/j.compedu.2007.01.002

Claggett, J. L., \& Goodhue, D. L. (2011, January). Have IS researchers lost bandura's self-efficacy concept? A discussion of the definition and measurement of computer self-efficacy. Paper presented at the 44th Hawaii International Conference on System Sciences (HICSS). Retrieved from http://www.hicss.hawaii.edu/hicss_44/bp44/os8.pdf

Colliver, J. A., Conlee, M. J., \& Verhulst, S. J. (2012). From test validity to construct validity ... and back? Medical Education, 46(4), 366-371. doi:10.1111/j.1365-2923.2011.04194.x

Compeau, D. R., \& Higgins, C. A. (1995). Computer self-efficacy: development of a measure and initial test. MIS Quarterly, 19(2), 189-211.

Davis, F. D. (1989). Perceived usefulness, perceived ease of use, and user acceptance of information technology. MIS Quarterly, 13(3), 9-340. Retrieved from http://www.jstor.org/pss/249008

Dillon, A. (2001). User acceptance of information technology. In W. Karwowski (Ed.), Encyclopaedia of Human Factors and Ergonomics. London: Taylor and Francis.

Dillon, A., \& Morris, M. (1996). User acceptance of new information technology: theories and models. In M. Williams (Ed.), Annual Review of Information Science and Technology (Vol. 31, pp. 3-32). Medford, NJ: Information Today.

Ding, L., Velicer, W. F., \& Harlow, L. L. (1995). Effects of estimation methods, number indicators per factor, and improper solutions on structural equation modeling fit indices. Structural Equation Modeling: A Multidisciplinary Journal, 2, 119-144. doi:10.1080/10705519509540000

Downey, J. P., \& McMurtrey, M. (2007). Introducing task-based general computer self-efficacy: An empirical comparison of three general self-efficacy instruments. Interacting with Computers, 19(3), 382-396. doi:10.1016/j.intcom.2006.11.001

Eastin, M. S., \& LaRose, R. (2000). Internet self-efficacy and the psychology of the digital divide. Journal of Computer-Mediated Communication, 6(1). doi:10.1111/j.1083-6101.2000.tb00110.x 
Embi, R. (2007). Computer anxiety and computer self-efficacy among Accounting educators at Universiti Teknologi Mara (uitm), Malaysia. (Unpublished doctoral dissertation). Virginia Polytechnic Institute and State University, Blacksburg, Virginia.

Hasan, B., \& Ahmed, M. U. (2010). A path analysis of the impact of application-specific perceptions of computer self-efficacy and anxiety on technology acceptance. Journal of Organizational and End User Computing, 22(3), 82-95.

Hoe, S. L. (2008). Issues and procedures in adopting structural equation modeling technique. Journal of Applied Quantitative Methods, 3(1), 76-83. Retrieved from http://jaqm.ro/issues/volume-3,issue$1 /$ pdfs/hoe.pdf

Hoelter, D. R. (1983). The analysis of covariance structures: Goodness-of-fit indices. Sociological Methods and Research, 11,325-344. doi:10.1177/0049124183011003003

Hsbollah, H. M., \& Idris, K. M. (2009). E-learning adoption: the role of relative advantages, trialability and academic specialisation. Campus-Wide Information Systems, 26(1), 54-70. doi:10.1108/10650740910921564

Kennedy, G., Dalgarno, B., Bennett, S., Judd, T., Gray, K., \& Chang, R. (2008, December). Immigrants and natives: Investigating differences between staff and students' use of technology. Paper presented at the ascilite 2008, Melbourne. Retrieved from http://www.ascilite.org.au/conferences/melbourne08/procs/kennedy.pdf

Kenny, R. F., Park, C. L., Van Neste-Kenny, J. M. C., \& Burton, P. (2010, October). Mobile Self Efficacy in Canadian Nursing Education Programs. Paper presented at the mLearn 2010, the 9th World Conference on Mobile Learning, Valletta, Malta. Retrieved from http://hdl.handle.net/2149/2767

Lee, Y., Kozar, K. A., \& Larsen, K. R. T. (2003). The technology acceptance model: Past, present, and future The Communications of the Association for Information Systems, 12, 751-780.

Lefoe, G., Olney, I. W., Wright, R., \& Herrington, A. (2009). Faculty development for new technologies: Putting mobile learning in the hands of the teachers. In J. Herrington, A. Herrington, J. Mantei, I. Olney \& B. Ferry (Eds.), New technologies, new pedagogies: Mobile learning in higher education. Wollongong, Australia: University of Wollongong.

Lu, X., \& Viehland, D. (2008, December). Factors influencing the adoption of mobile learning. Paper presented at the 19th Australasian Conference on Information Systems, Christchurch.

Ma, Q., \& Liu, L. (2004). The technology acceptance model: A meta-analysis of empirical findings. Journal of Organizational and End User Computing, 16(1), 59-72. doi:10.4018/978-1-59904-9458.ch079

MacCallum, R. (1986). Specification searches in covariance structure modeling. Psychological Bulletin, 100(1), 107-120. doi:10.1037/0033-2909.100.1.107

Mulaik, S. A., \& Millsap, R. E. (2000). Doing the four-step right. Structural Equation Modeling: A Multidisciplinary Journal, 7(1), 36-73. doi:10.1207/S15328007SEM0701_02

Naismith, L., Lonsdale, P., Vavoula, G., \& Sharples, M. (2005). Literature review in mobile technologies and learning. NESTA Futurelab Series. Retrieved from http://citeseerx.ist.psu.edu/viewdoc/download?doi=10.1.1.136.2203\&rep=rep1\&type=pdf

Nunnally, J. C., \& Bernstein, I. H. (1994). Psychometric Theory (3rd ed.). New York: McGraw-Hill.

Paraskeva, F., Bouta, H., \& Papagianni, A. (2008). Individual characteristics and computer self-efficacy in secondary education teachers to integrate technology in educational practice. Computers \& Education, 50(3), 1084-1091. doi:10.1016/j.compedu.2006.10.006 
Park, Y., \& Chen, J. (2007). Acceptance and adoption of the innovative use of smartphone. Industrial Management and Data Systems, 107(9), 1349-1365. doi:10.1108/02635570710834009

Pachler, N., Bachmair, B., Cook, J. (2010). Mobile learning structures, agency, practices. New York: Springer.

Potosky, D. (2002). A field study of computer efficacy beliefs as an outcome of training: the role of computer playfulness, computer knowledge, and performance during training. Computers in Human Behavior, 18(3), 241-255. doi:10.1016/s0747-5632(01)00050-4

Punch, K. (2009). Introduction to research methods in education. London: SAGE.

Rogers, E. M. (2003). Diffusion of innovations (5th ed.). New York, NY: Free Press.

Saadé, R. G., \& Kira, D. (2007). Mediating the impact of technology usage on perceived ease of use by anxiety. Computers \& Education, 49(4), 1189-1204. doi:10.1016/j.compedu.2006.01.009

Schumacker, R. E., \& Lomax, R. G. (2010). A beginner's guide to structural equation modeling (3rd ed.). New York, N.Y.: Routledge Academic.

Shih, H.-P. (2006). Assessing the effects of self-efficacy and competence on individual satisfaction with computer use: an IT student perspective. Computers in Human Behavior, 22(6), 1012-1026. doi:10.1016/j.chb.2004.03.025

Shih, P.-C., Muñoz, D., \& Sánchez, F. (2006). The effect of previous experience with information and communication technologies on performance in a web-based learning program. Computers in Human Behavior, 22(6), 962-970. doi:10.1016/j.chb.2004.03.016

Sivo, S. A., Fan, X. T., Witta, E. L., \& Willse, J. T. (2006). The search for 'optimal' cutoff properties: Fit index criteria in structural equation modeling. The Journal of Experimental Education, 74(3), $267-$ 289. doi:10.3200/JEXE.74.3.267-288

Teo, T. (2010). A path analysis of pre-service teachers' attitudes to computer use: applying and extending the technology acceptance model in an educational context. Interactive Learning Environments, 18(1), $65-79$.

Theng, Y.-L. (2009, June). Mobile learning for tertiary students: an exploratory study of acceptance of use. Paper presented at the World Conference on Educational Multimedia, Hypermedia and Telecommunications 2009, Honolulu, HI, USA. Retrieved from http://www.editlib.org/p/31606

Usher, E. L., \& Pajares, F. (2008). Sources of self-efficacy in school: Critical review of the literature and future directions. Review of Educational Research, 78(4), 751-796.

Uzunboylu, H., \& Ozdamli, F. (2011). Teacher perception for m-learning: scale development and teachers' perceptions. Journal of Computer Assisted Learning, 27. doi:10.1111/j.13652729.2011.00415.x

Venkatesh, V., \& Davis, F. D. (2000). A theoretical extension of the technology acceptance model: Four longitudinal field studies. Management Science, 46, 186-204. doi:10.1287/mnsc.46.2.186.11926

Venkatesh, V., Morris, M. G., Gordon, B. D., \& Davis, F. D. (2003). User acceptance of information technology: Toward a unified view. MIS Quarterly, 27(3), 425-478. doi: 10.2190/EC.40.1.d

Wang, W.-T., \& Wang, C.-C. (2009). An empirical study of instructor adoption of web-based learning systems. Computers \& Education, 53(3), 761-774. 
Williams, P. W. (2009). Assessing mobile learning effectiveness and acceptance (Doctoral dissitation, George Washington University, Washington, USA). Retrieved from http://www.paulwwilliamsphd.com/index_files/Assessing_Mobile_Learning_Effectiveness_and_Acce ptance.pdf

Wilson, F., Kickul, J., \& Marlino, D. (2007). Gender, entrepreneurial self-efficacy, and entrepreneurial career intentions: implications for entrepreneurship education. Entrepreneurship Theory and Practice, 31(3), 387-406. doi:10.1111/j.1540-6520.2007.00179.x

Zikmund, W. (2000). Business research methods (6th ed.). Fort Worth, TX: Harcourt College Publishers.

Corresponding author: Kathryn Mac Callum, kmaccallum@eit.ac.nz

Australasian Journal of Educational Technology (C) 2013.

Please cite as: Mac Callum, K., \& Jeffrey, L. (2013). The influence of students' ICT skills and their adoption of mobile learning. Australasian Journal of Educational Technology, 29(3), 303-314. 